\title{
Designing Filter for Certain Subclasses of Analytic Univalent Functions
}

\author{
P. Murugabharathi ${ }^{1}$, B. Srutha Keerthi ${ }^{2}$ \\ ${ }^{1}$ Mathematics Division,School of Advanced Sciences, VIT Chennai,Chennai - 600 127, India \\ ${ }^{1}$ Mathematics Division,School of Advanced Sciences, VIT Chennai,Chennai - 600 127, India
}

\section{Article Info}

Article history:

Received Feb $12^{\text {th }}, 2018$

Revised Apr 20 ${ }^{\text {th }}, 2018$

Accepted Apr 26 ${ }^{\text {th }}, 2018$

\author{
ABSTRACT \\ In this paper we consider certain subclasses of analytic univalent functions \\ and plot a frequency response of appropriate circuit for both amplitude and \\ phase with changing source frequency. \\ Mathematics Subject Classification, 2010: 30C45.
}

\section{Keyword:}

Bandpass filter

Highpass filter

Time response

Starlike function

Sakaguchi type function

\section{Corresponding Author:}

P.MURUGABHARATHI,

Mathematics Division

School of Advanced Sciences, VIT Chennai,

Chennai - 600 127, India

bharathi.muhi@gmail.com

\section{Introduction}

Let $A$ be the class of functions $f(z)$ of the form

$$
\mathrm{f}(\mathrm{z})=\mathrm{z}+\sum_{\mathrm{n}=2}^{\infty} \mathrm{a}_{\mathrm{n}} \mathrm{z}^{\mathrm{n}}
$$

which are analytic in the open unit disk $\Delta=\{\mathrm{z} \in \mathrm{C}:|\mathrm{z}|<1\}$.We also denoteby $\mathrm{S}$ the class of all functions in the normalized analytic function class $A$ which are univalent in $\Delta$. Goodman[4] introduced the subclasses of $\mathrm{S}$. The class $\mathrm{S}$ *of all starlike functions with respect to the origin.

A function $\mathrm{f} \in \mathrm{A}$ is said to be starlike with respect to the origin if it maps $\Delta$ onto a Starlike domain with respect to the origin. Robertson [5] gave necessary and sufficient condition for class $S^{*}$ is $\operatorname{Re} \frac{z f^{\prime}(z)}{f(z)}>0, z \in \Delta$. For $0 \leq \lambda \leq 1,|t| \leq 1$ and $t \neq 1$, a function $f \in A$ given by (1.1) is said to be in the clas $P(\alpha, \lambda, t)$ ifthefollowing conditions are satisfied the analytic characterization

$$
\operatorname{Re} \frac{(1-t) z f_{\prime}^{\prime}(z)}{(1-\lambda)[f(z)-f(t z)]+\lambda z\left[f^{\prime(z)}-t f^{\prime}(t z)\right]}>\alpha, \quad z \in \Delta
$$

Recently these kind of classes were studied by Srutha keerthi and et.al[6]. 
Analysis of a circuit with varying frequency of sinusoidal sources is called the frequency response of a circuit. Frequency selection in the circuits is called filters because of their ability to filter out certain input signals on the basis of frequency. Using transfer function of circuit, we plot a frequency response of the circuit for both amplitude and phase with changing source frequency. One graph of $|\mathrm{H}(\mathrm{j} \omega)|$ versus frequency $\mathrm{j} \omega$. It is called the Magnitude plot.

One graph of $\theta(j \omega)$ versus frequency $\omega$. It is called the Phase Angle plot.

A Low-Pass filterpasses signals at frequencies lower than the cutoff frequency from the input to the output. A High-Pass filterpasses signals at frequencies higher than the cutoff frequency from the input to the output. A Band-Pass filter passes signals within the band defined by two cutoff frequencies from the input to the output.

\subsection{Frequency response of a rlc circuit (bandpass filter)}

Let us consider the function $\frac{z}{1+z+z^{\wedge} 2}$ belongs to the class of all analytic univalent function with the Montel normalization (ie $\frac{z}{1+z+z^{\wedge} 2} \in S$ ), which is a transfer function for the RLC circuit in series. Using transfer function of circuit, we plot a frequency response of the circuit for both amplitudeand phasewith changing source frequency. For the above transfer function $R L C$ values are $R=1 ; L=1 ; C=1$;

\begin{tabular}{|c|c|c|c|c|c|}
\hline Matlab code & Output & & & & \\
\hline 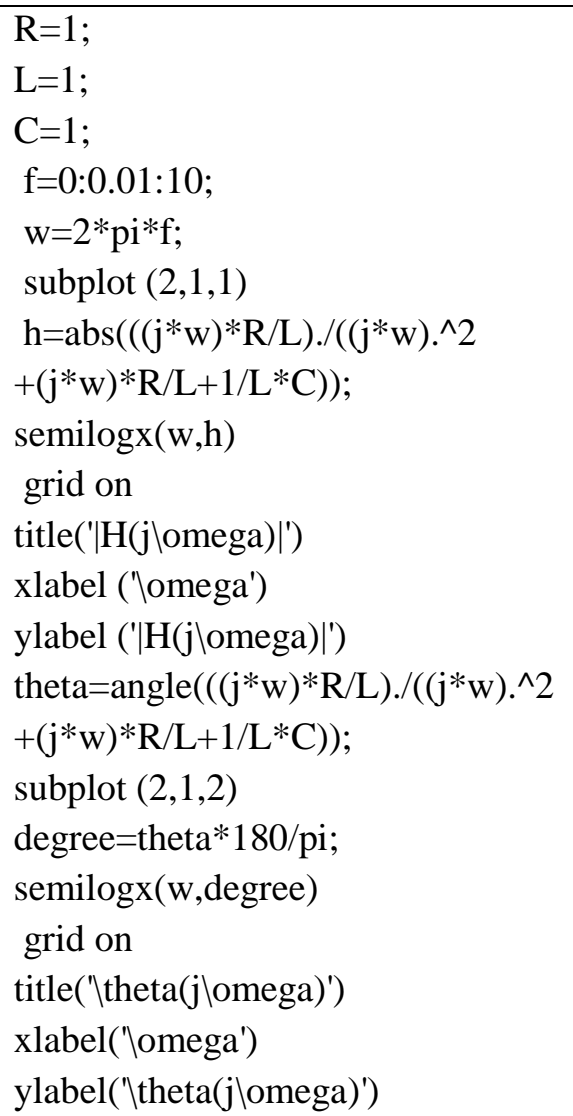 & 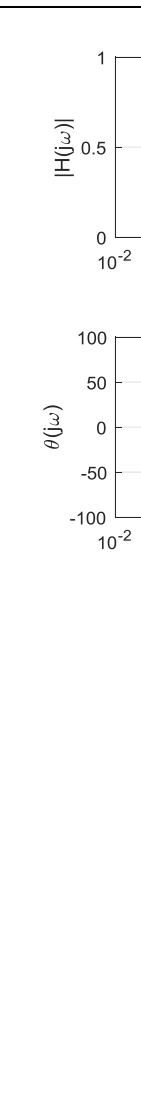 & $10^{-1}$ & $\begin{array}{c}10^{0} \\
\omega \\
\theta(j \omega)\end{array}$ & $\frac{w 1}{10^{1}}$ & $=$ \\
\hline
\end{tabular}

The Bode plot is a convenient tool for investigating the bandpass characteristics of the RLC network. Use tf to specify the circuit's transfer function for the values 


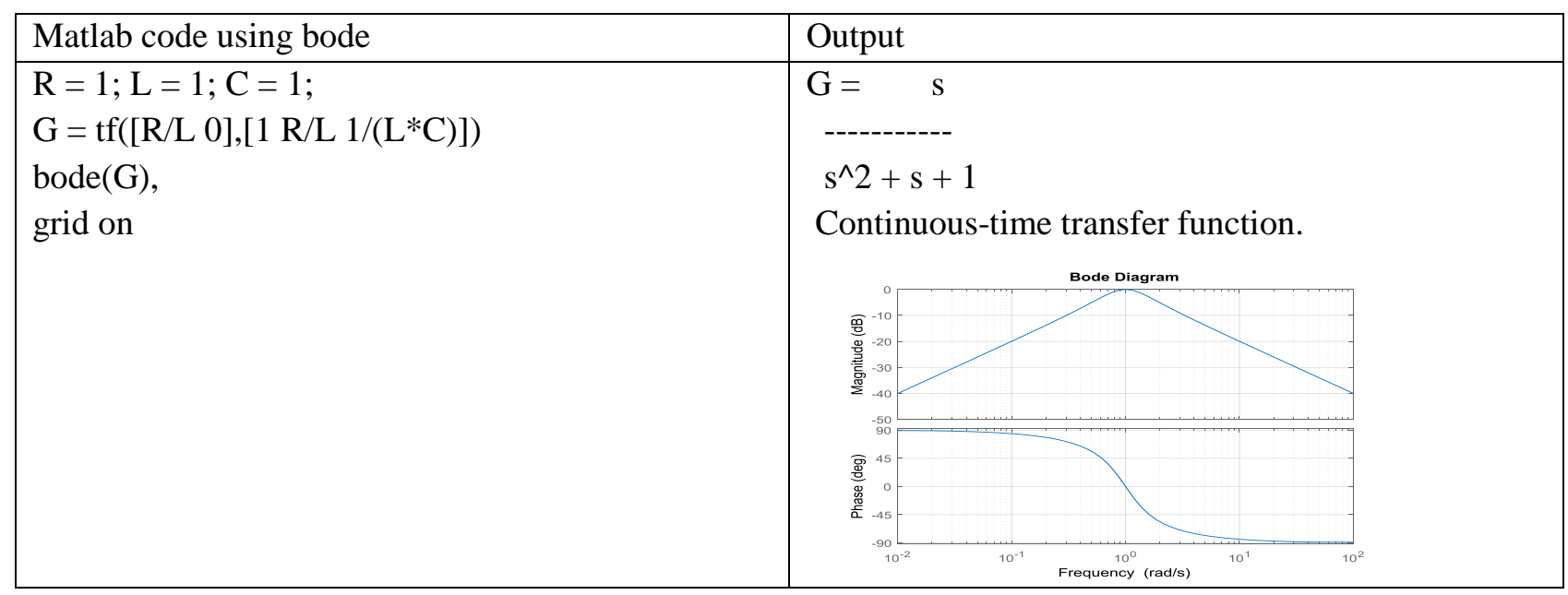

The transfer function from input to output voltage is:

$$
G(s) \frac{\frac{s R}{L}}{s^{2}+\frac{s R}{L}+\frac{1}{L C}}
$$

To build a bandpass filter tuned to the frequency $1 \mathrm{rad} / \mathrm{s}$, set $\mathrm{L}=\mathrm{C}=1$ and use $\mathrm{R}$ to tune the filter band.To get a narrower passing band, try decreasing values of $\mathrm{R}$ as follows
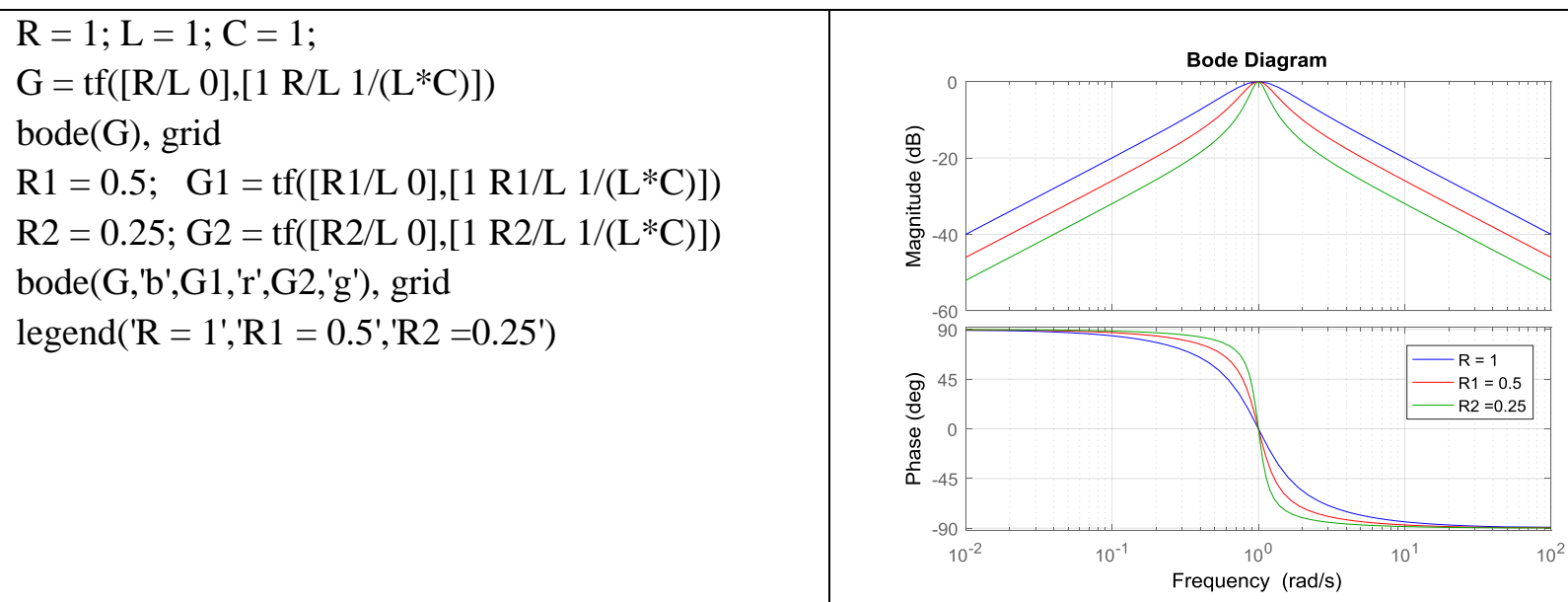

The resistor value $\mathrm{R}=0.25$ gives a filter narrowly tuned around the target frequency of $1 \mathrm{rad} / \mathrm{s}$.

\subsection{Time response of the circuit}

We can confirm the attenuation properties of the circuit $\mathrm{G} 2(\mathrm{R}=0.25)$ by simulating how this filter transforms sine waves with frequency $0.9,1$, and $1.1 \mathrm{rad} / \mathrm{s}$ : 


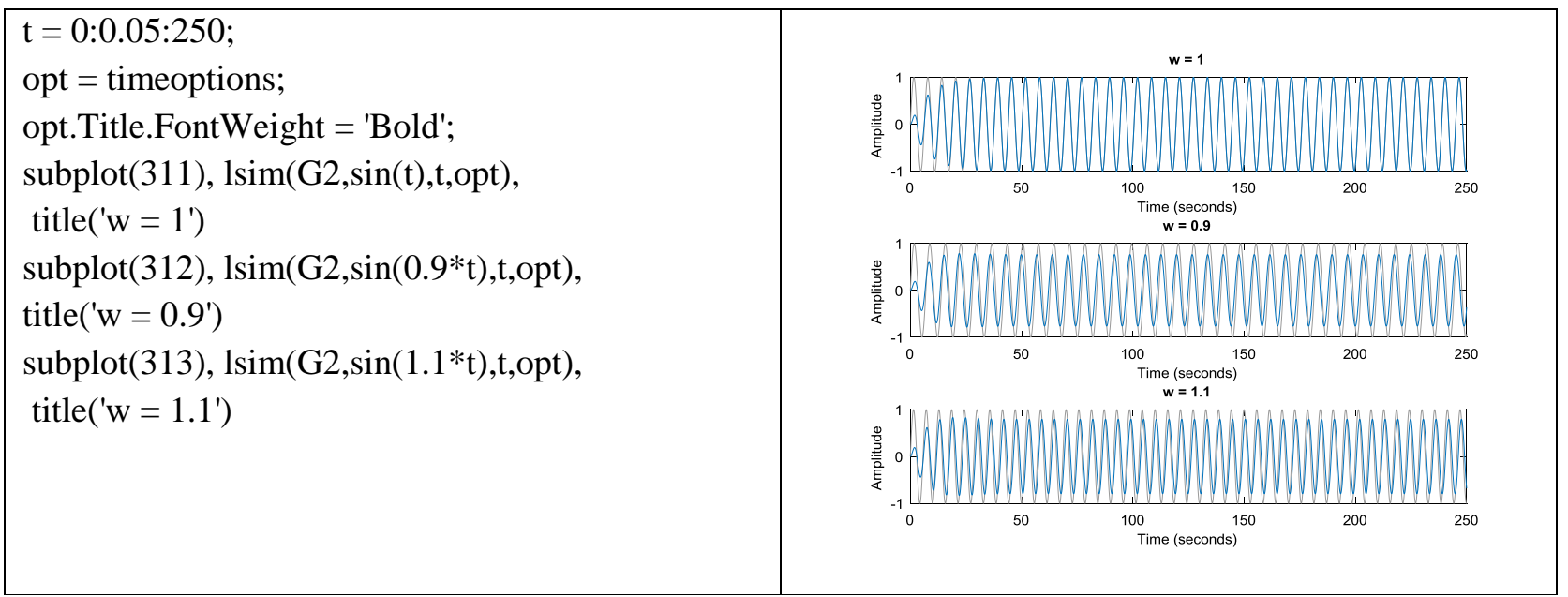

The waves at 0.9 and $1.1 \mathrm{rad} / \mathrm{s}$ are considerably attenuated. The wave at $1 \mathrm{rad} / \mathrm{s}$ comes out unchanged once the transients have died off.

\section{Frequency response of rl circuit (lowpass filter)}

For the case $\lambda=0.2, \mathrm{f}=\frac{z}{(1+\mathrm{z})}, \mathrm{t}=0$ and $\alpha=0$ in $P(\alpha, \lambda, t)$ we get the function $H(z)=$ $\frac{5}{4 \mathrm{z}+5}$ which is a transfer function for the RL circuit in series. Using transfer function of circuit, we plot a frequency response of the circuit. For the above transfer function $\mathrm{RL}$ values are $\mathrm{R}=1 ; \mathrm{L}=0.8$;

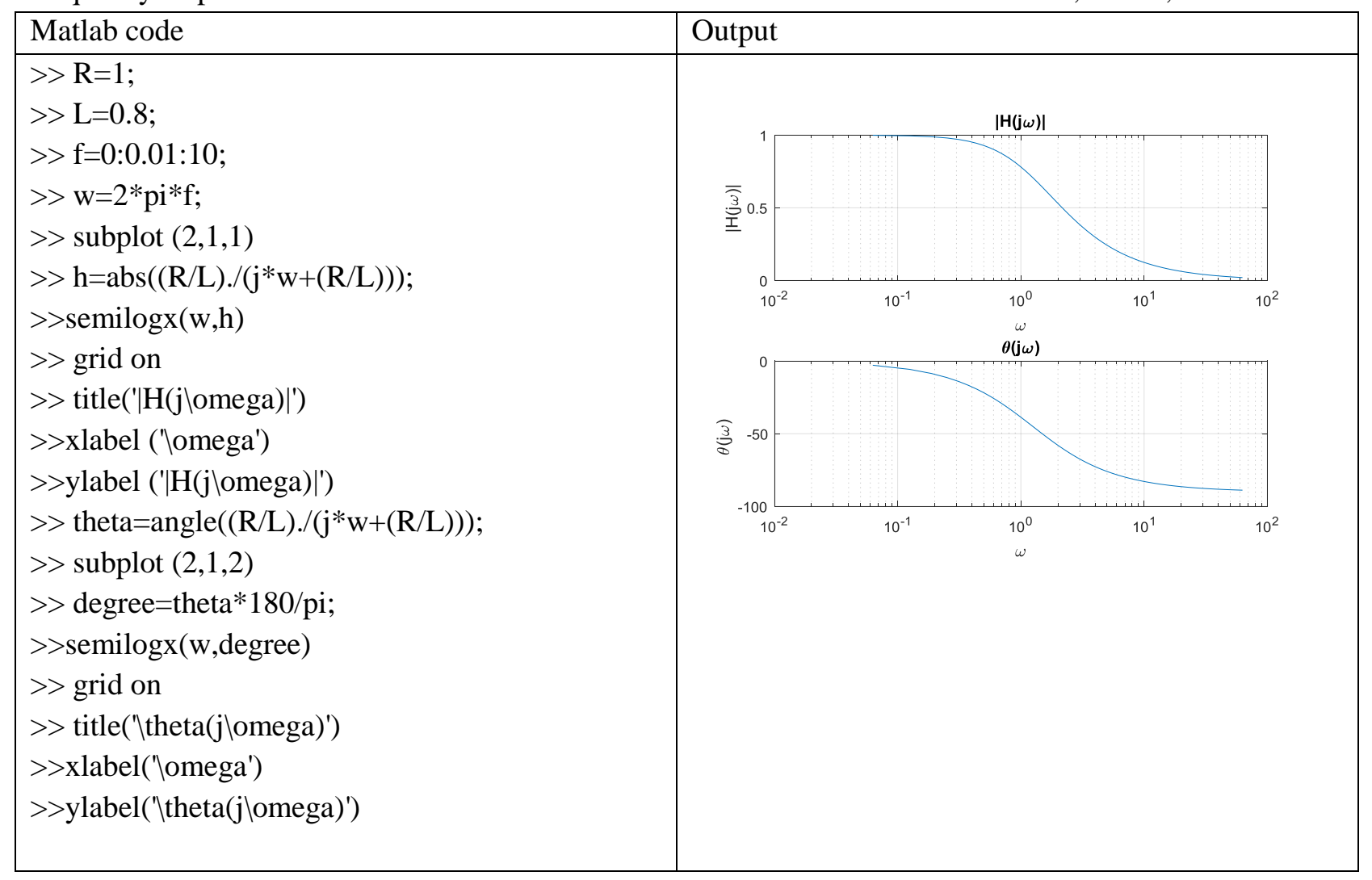

The Bode plot is a convenient tool for investigating the lowpass characteristics of the RL network. Use tf to specify the circuit's transfer function for the values. 


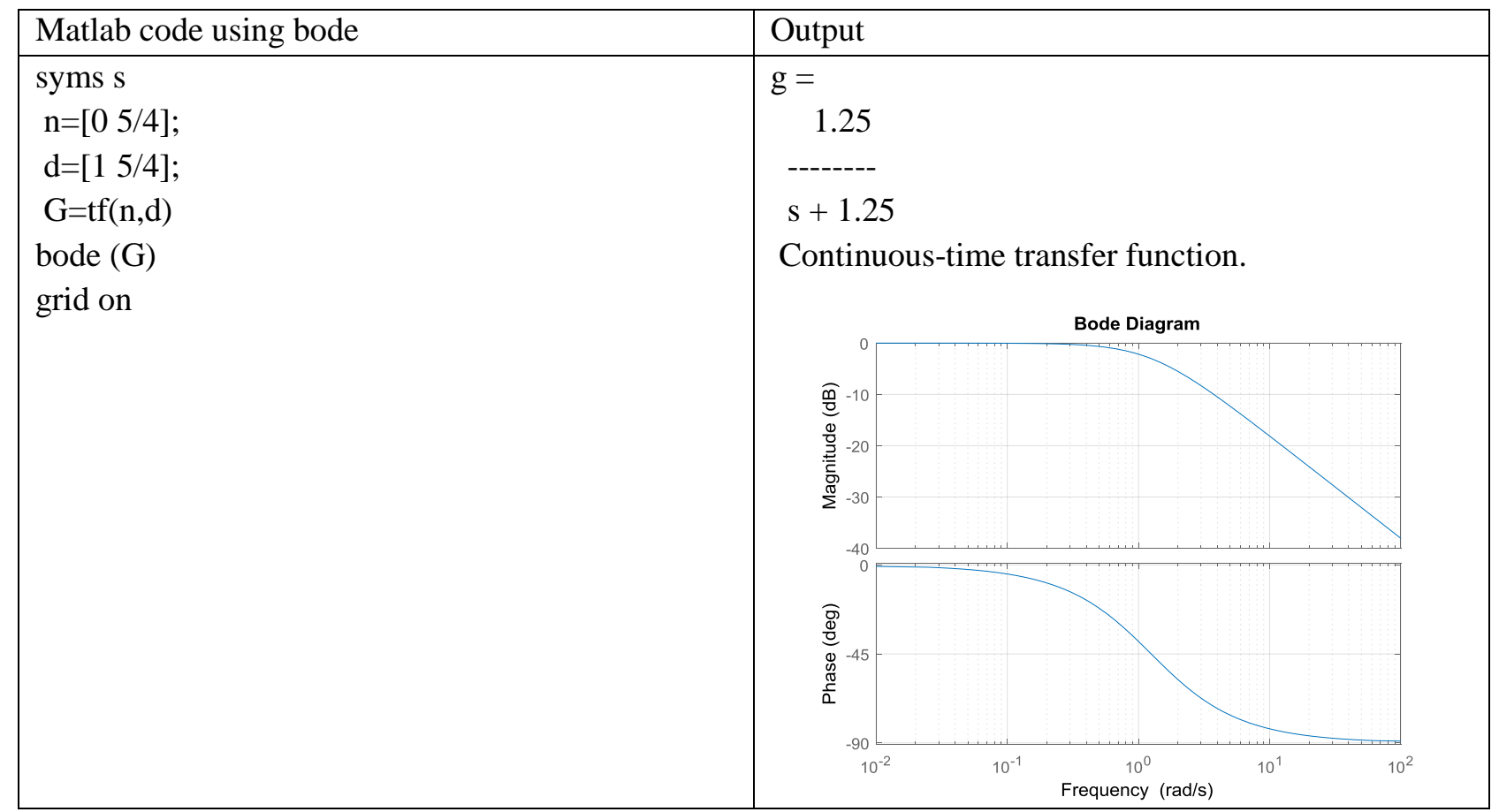

The transfer function from input to output voltage is:

$$
G(s) \frac{\frac{R}{L}}{s+\frac{R}{L}}
$$

To build a bandpass filter tuned to the frequency $1 \mathrm{rad} / \mathrm{s}$, set $\mathrm{L}=4 / 5$ and use $\mathrm{R}$ to tune the filter band. To get a narrower passing band, try decreasing values of $\mathrm{R}$ as follows

\begin{tabular}{|l|l|l|l|}
\hline $\mathrm{R}=1 ; \mathrm{L}=4 / 5 ;$ & \\
$\mathrm{G}=\mathrm{tf}([\mathrm{R} / \mathrm{L}],[1 \mathrm{R} / \mathrm{L}])$ & \\
bode(G), grid & \\
$\mathrm{R} 1=5 ; \mathrm{G} 1=\mathrm{tf}([\mathrm{R} 1 / \mathrm{L}],[1 \mathrm{R} 1 / \mathrm{L}]) ;$ \\
$\mathrm{R} 2=20 ; \mathrm{G} 2=\mathrm{tf}([\mathrm{R} 2 / \mathrm{L}],[1 \mathrm{R} 2 / \mathrm{L}]) ;$ \\
bode(G,'b',G1,'r',G2,'g'), grid
\end{tabular}

The resistor value $\mathrm{R}=1$ gives a filter narrowly tuned around the target frequency of $1 \mathrm{rad} / \mathrm{s}$.

\section{1 time response of the circuit}

We can confirm the attenuation properties of the circuit $\mathrm{G} 2(\mathrm{R}=1)$ by simulating how this filter transforms sine waves with frequency $0.5,1$, and $1.5 \mathrm{rad} / \mathrm{s}$ : 
$\mathrm{t}=0: 0.05: 250$;

opt = timeoptions;

opt.Title.FontWeight = 'Bold';

$\operatorname{subplot}(311), \quad \operatorname{lsim}(\mathrm{G}, \sin (0.5 * \mathrm{t}), \mathrm{t}, \mathrm{opt}), \quad$ title('w = $\left.0.5^{\prime}\right)$

subplot(312), $\lim (\mathrm{G}, \sin (1 * \mathrm{t}), \mathrm{t}, \mathrm{opt})$, title('w = 1')

subplot(313), $\operatorname{lsim}(\mathrm{G}, \sin (1.5 * \mathrm{t}), \mathrm{t}, \mathrm{opt}), \quad \operatorname{title}(\mathrm{w}=$ $\left.1.5^{\prime}\right)$
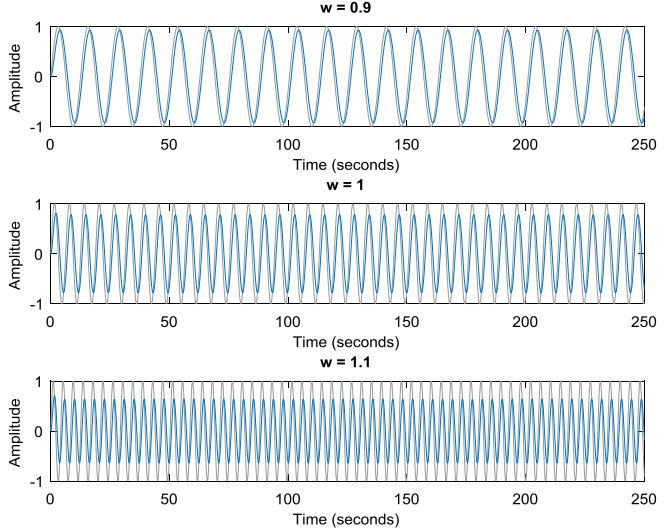

The waves at 1 and $1.1 \mathrm{rad} / \mathrm{s}$ are considerably attenuated. The wave at $0.9 \mathrm{rad} / \mathrm{s}$ comes out unchanged once the transients have died off.

\section{Frequency response of rc circuit (lowpass filter)}

$\mathrm{H}(\mathrm{z})$ is also a transfer function for the $\mathrm{RC}$ circuit in series. Using transfer function of circuit, we plot a frequency response of the circuit for both amplitude and phase with changing source frequency. For the above transfer function $\mathrm{RC}$ values $\mathrm{R}=1 ; \mathrm{C}=0.8$;

\begin{tabular}{|c|c|c|c|c|c|}
\hline Matlab code & Output & & & & \\
\hline $\begin{array}{l}\mathrm{R}=1 ; \\
\mathrm{C}=0.8 ; \\
\mathrm{f}=0: 0.01: 10 ; \\
\mathrm{w}=2 * \mathrm{pi}{ }^{*} \mathrm{f} ; \\
\mathrm{h}=\mathrm{abs}\left((1 /(\mathrm{R} * \mathrm{C})) . /\left(\mathrm{j}^{*} \mathrm{~W}+1 /\left(\mathrm{R}^{*} \mathrm{C}\right)\right)\right) ; \\
\text { subplot }(2,1,1) \\
\text { semilogx }(\mathrm{w}, \mathrm{h}) \\
\text { grid on } \\
\text { title('|H(jlomega)') } \\
\text { xlabel ('lomega') } \\
\text { ylabel }\left(\mid \mathrm{H}(\mathrm{jlomega})^{\prime}\right) \\
\text { theta=angle((1/(R*C))./(j*w+1/(R*C))); } \\
\text { subplot }(2,1,2) \\
\text { degree=theta*180/pi; } \\
\text { semilogx }(\mathrm{w}, \text { degree }) \\
\text { grid on } \\
\text { title('Itheta(jlomega)') } \\
\text { xlabel('lomega') } \\
\text { ylabel('Itheta(jlomega)') }\end{array}$ & 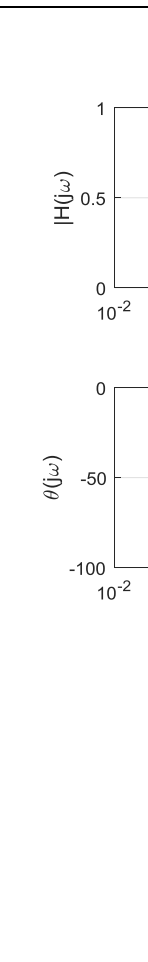 & $10^{-1}$ & $\begin{array}{c}10^{0} \\
\omega \\
\theta(j \omega)\end{array}$ & $10^{1}$ & $10^{2}$ \\
\hline
\end{tabular}

The transfer function from input to output voltage is:

$G(s) \frac{\frac{1}{R C}}{s+\frac{1}{R C}}$

To build a lowpass filter tuned to the frequency $1 \mathrm{rad} / \mathrm{s}$, set $\mathrm{C}=0.8$ and use $\mathrm{R}$ to tune the 
filter band. To get a narrower passing band, try increasing values of $\mathrm{R}$ as follows

\begin{tabular}{|l|l|l|}
\hline $\mathrm{R}=1 ; \mathrm{C}=0.8 ;$ \\
$\mathrm{G}=\mathrm{tf}([1 /(\mathrm{R} * \mathrm{C})],[11 /(\mathrm{R} * \mathrm{C})])$ \\
bode(G), grid \\
$\mathrm{R} 1=5 ; \mathrm{G} 1=\mathrm{tf}([1 /(\mathrm{R} 1 * \mathrm{C})],[11 /(\mathrm{R} 1 * \mathrm{C})]) ;$ \\
$\mathrm{R} 2=20 ; \mathrm{G} 2=\mathrm{tf}([1 /(\mathrm{R} 2 * \mathrm{C})],[11 /(\mathrm{R} 2 * \mathrm{C})]) ;$ \\
bode(G,'b',G1,'r', $\left.\mathrm{G} 2, \mathrm{~g}^{\prime}\right)$, grid
\end{tabular}

The resistor value $\mathrm{R}=20$ gives a filter narrowly tuned around the target frequency of $1 \mathrm{rad} / \mathrm{s}$.

\section{1 analyzing the time response of the circuit}

We can confirm the attenuation properties of the circuit $\mathrm{G}(\mathrm{R}=1)$ by simulating how this filter transforms sine waves with frequency $0.5,1$, and $1.5 \mathrm{rad} / \mathrm{s}$ :
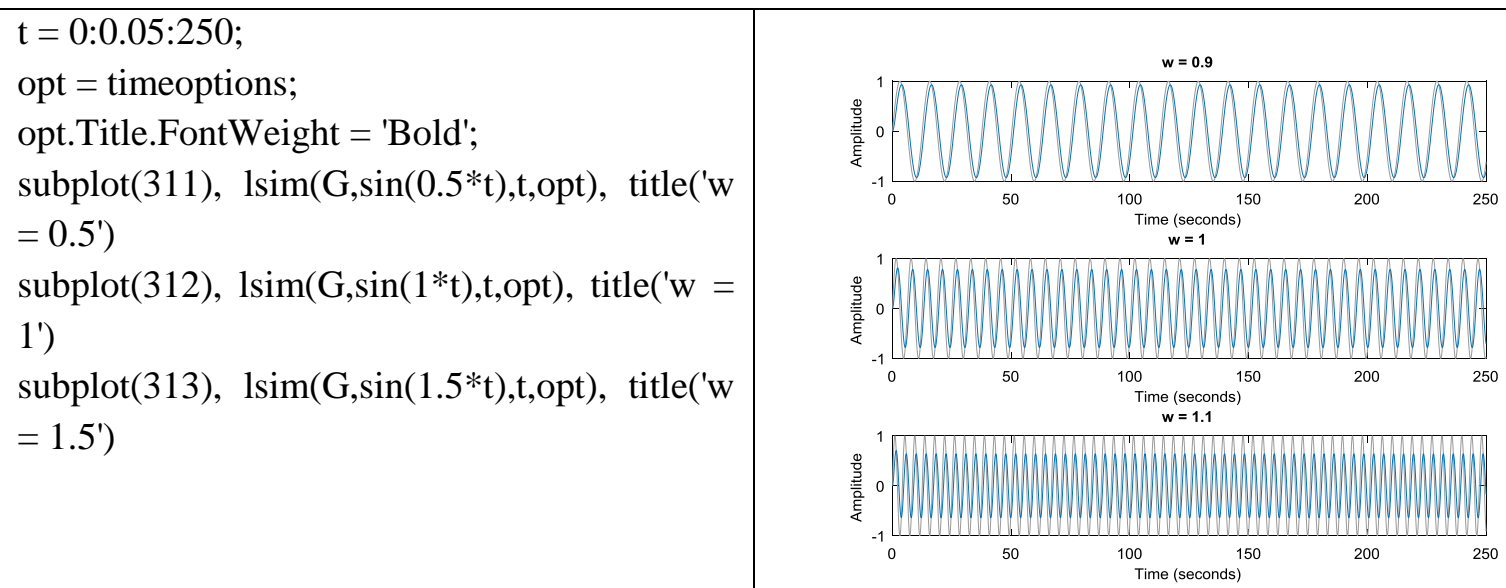

The waves at 1 and $1.1 \mathrm{rad} / \mathrm{s}$ are considerably attenuated. The wave at $0.9 \mathrm{rad} / \mathrm{s}$ comes out unchanged once the transients have died off.

\section{Frequency response of rl circuit (highpass filter)}

Let us consider the function $\frac{z}{1+z}$ belongs to the class of all analytic univalent function with the Montel normalization (ie. $\frac{z}{1+\mathrm{z}} \in S$ ), which is a transfer function for the RL circuit in series. Using transfer function of circuit,we plot a frequency response of the circuit. For the above transfer function RL values $R=1$; $\mathrm{L}=1$; 


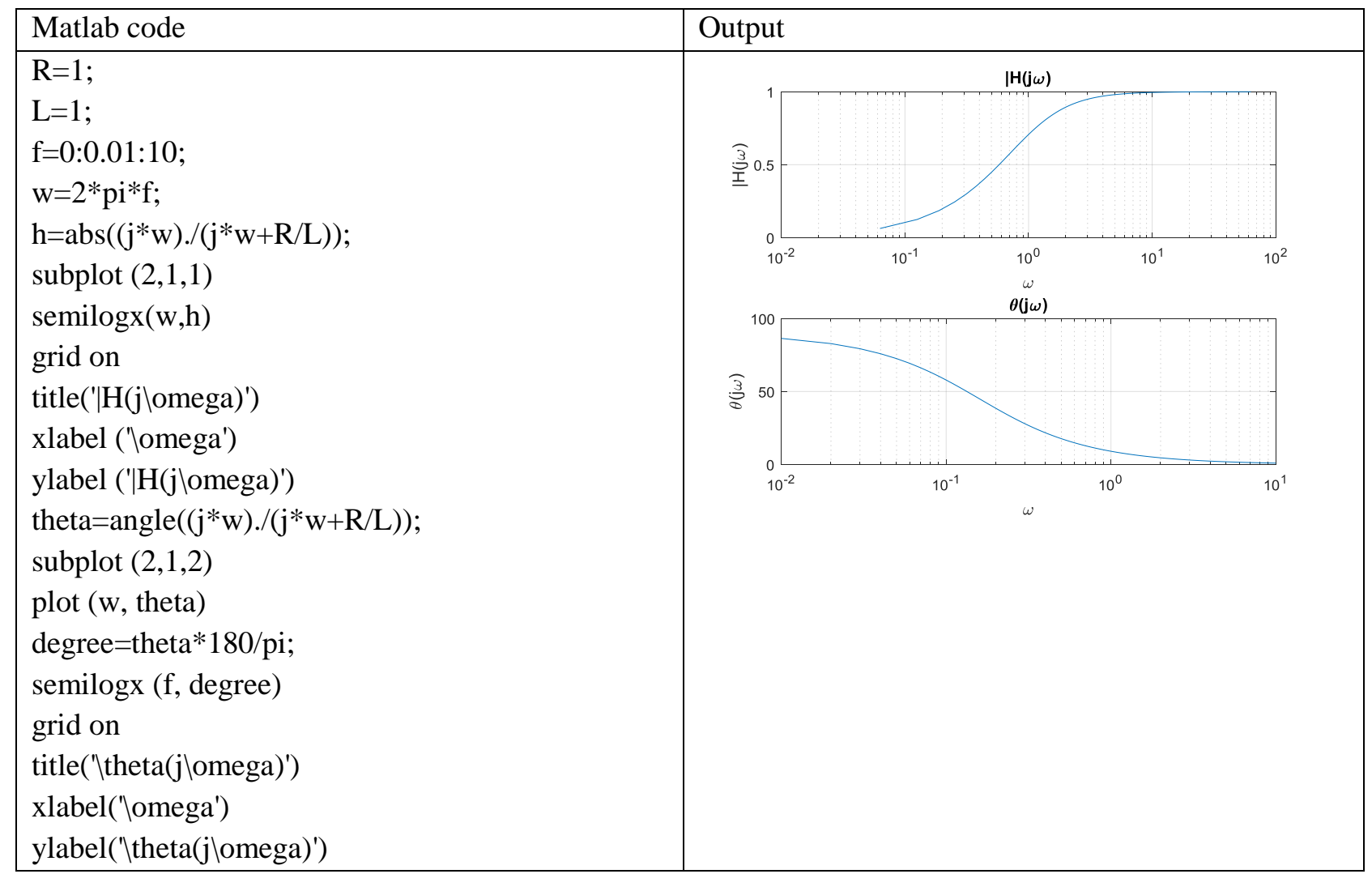

The Bode plot is a convenient tool for investigating the highpass characteristics of the RL network. Use tf to specify the circuit's transfer function for the values

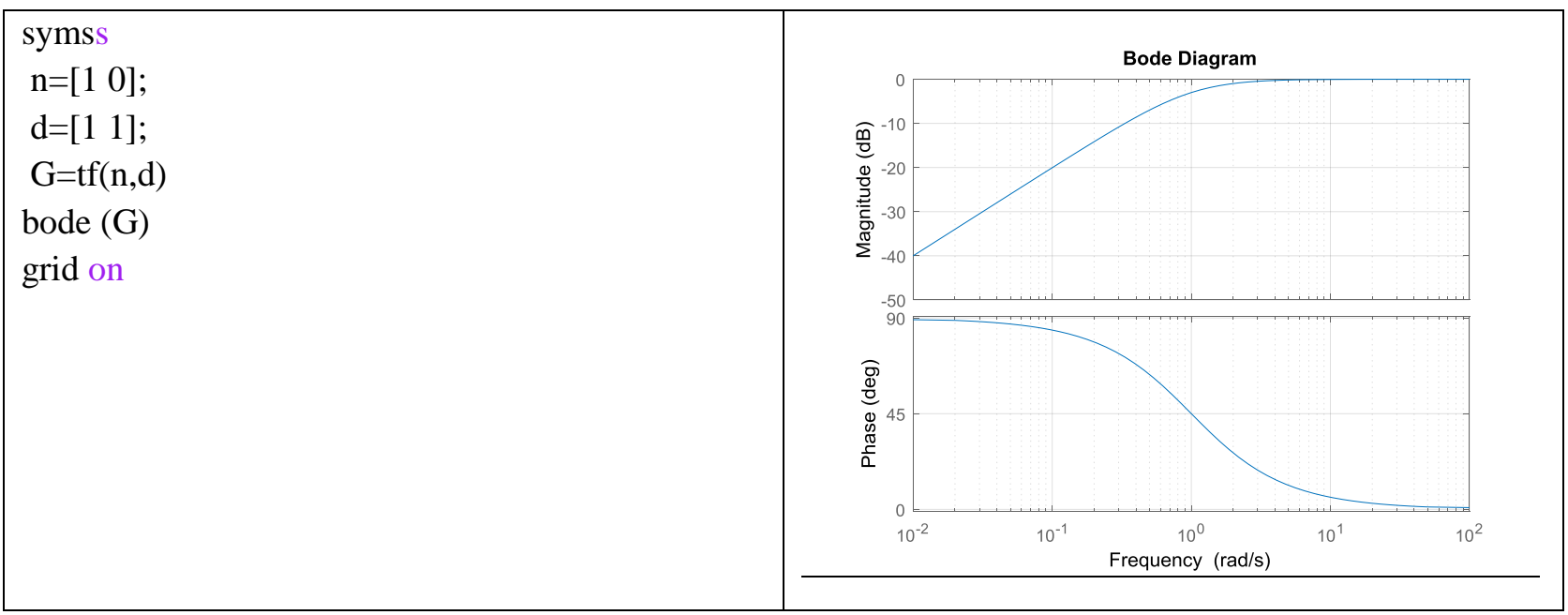

The transfer function from input to output voltage is:

$$
G(s) \frac{s}{s+\frac{R}{L}}
$$

To build a bandpass filter tuned to the frequency $1 \mathrm{rad} / \mathrm{s}$, set $\mathrm{L}=1$ and use $\mathrm{R}$ to tune the filter band. To get a narrower passing band, try decreasing values of $\mathrm{R}$ as follows 


$$
\begin{aligned}
& \mathrm{R}=1 ; \mathrm{L}=1 ; \\
& \mathrm{G}=\mathrm{tf}([10],[1 \mathrm{R} / \mathrm{L}]) \\
& \text { bode(G), grid } \\
& \mathrm{R} 1=5 ; \quad \mathrm{G} 1=\operatorname{tf}([10],[1 \mathrm{R} 1 / \mathrm{L}]) ; \\
& \mathrm{R} 2=20 ; \mathrm{G} 2=\mathrm{tf}([10],[1 \mathrm{R} 2 / \mathrm{L}]) ; \\
& \text { bode(G,'b',G1,'r',G2,'g'), grid } \\
& \text { legend('R = 1','R1 = 5','R2 = 20') }
\end{aligned}
$$

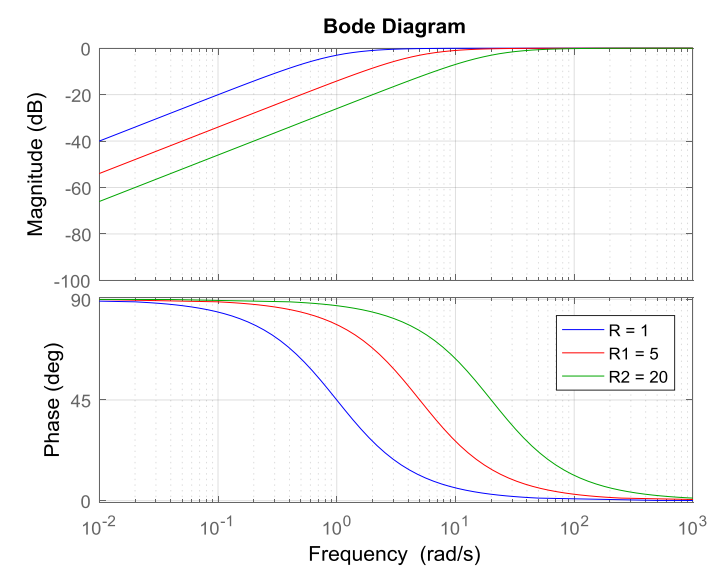

The resistor value $\mathrm{R}=20$ gives a filter narrowly tuned around the target frequency of $1 \mathrm{rad} / \mathrm{s}$.

\section{1 analyzing the time response of the circuit}

We can confirm the attenuation properties of the circuit $G(R=1)$ by simulating how this filter transforms sine waves with frequency $1,1.1$, and $2.5 \mathrm{rad} / \mathrm{s}$ :
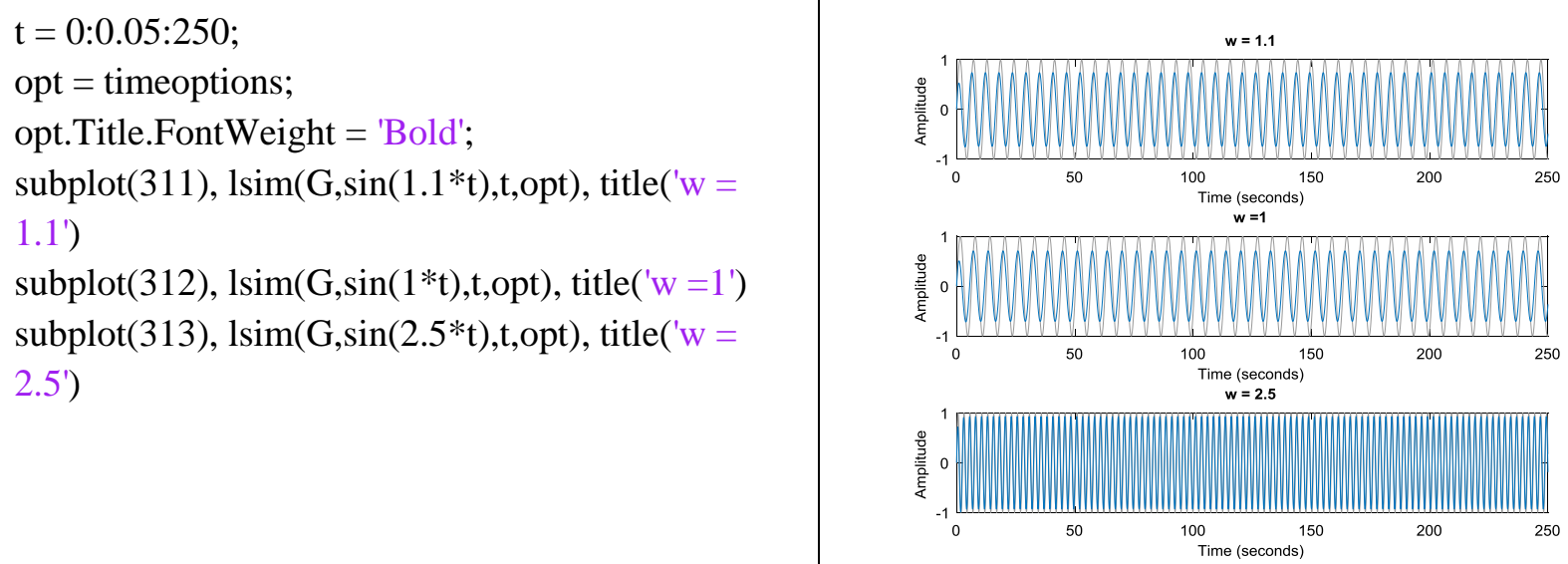

The waves at 1 and $1.1 \mathrm{rad} / \mathrm{s}$ are considerably attenuated. The wave at $2.5 \mathrm{rad} / \mathrm{s}$ comes out unchanged once the transients have died off.

\section{Frequency response of re circuit (highpass filter)}

Let us consider the function $\frac{z}{1+z}$ belongs to the class of all analytic univalent function with the Montel normalization (ie. $\frac{z}{1+\mathrm{z}} \in S$ ), which is a transfer function for the RC circuit in series.Using transfer function of circuit, we plot a frequency response of the circuit. For the above transfer function RC valuesare $\mathrm{R}=1 ; \mathrm{C}=1$; 


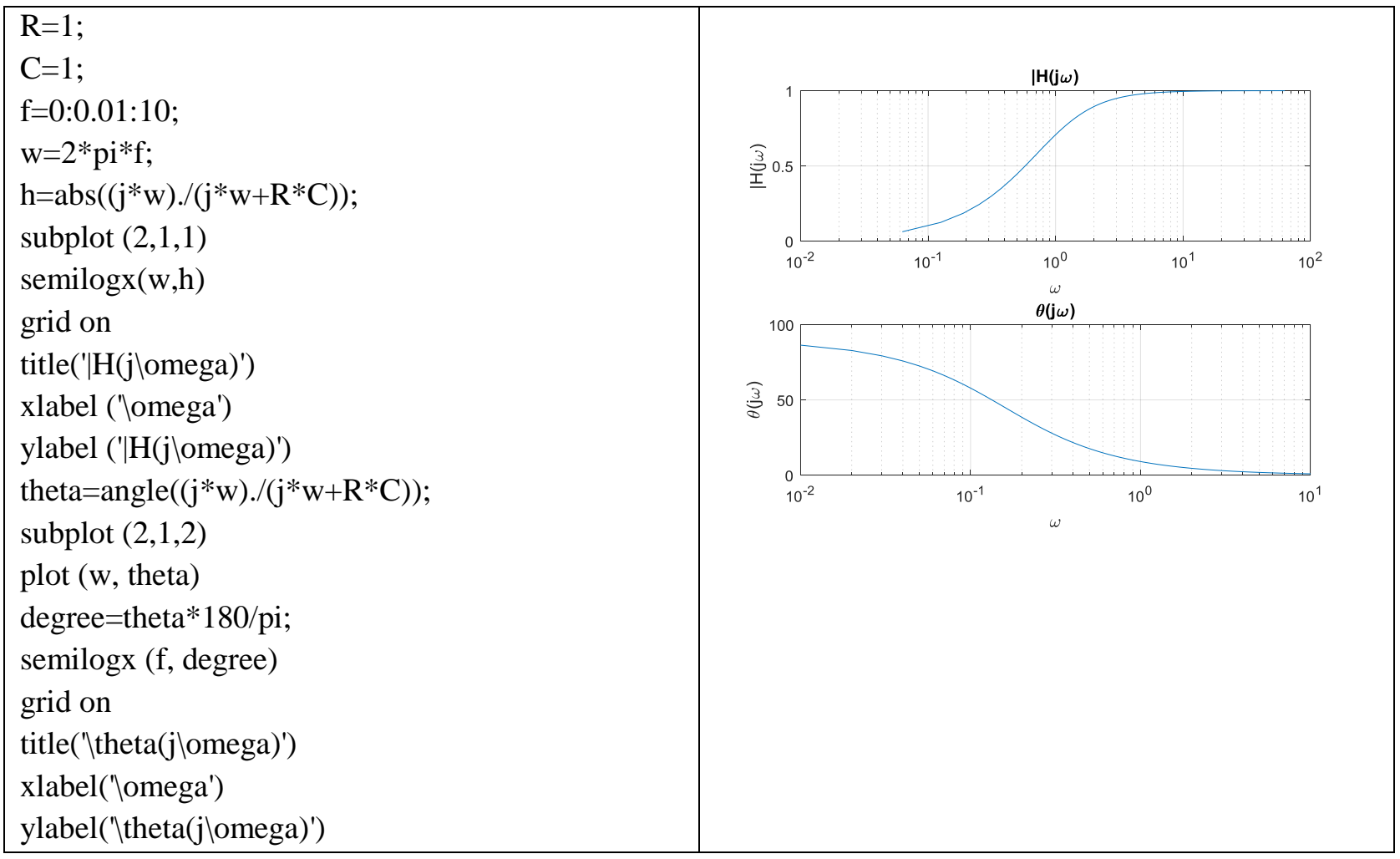

The transfer function from input to output voltage is:

$$
G(s) \frac{s}{s+R C}
$$

To build a bandpass filter tuned to the frequency $1 \mathrm{rad} / \mathrm{s}$, set $\mathrm{C}=1$ and use $\mathrm{R}$ to tune the filter band. To get a narrower passing band, try decreasing values of $\mathrm{R}$ as follows

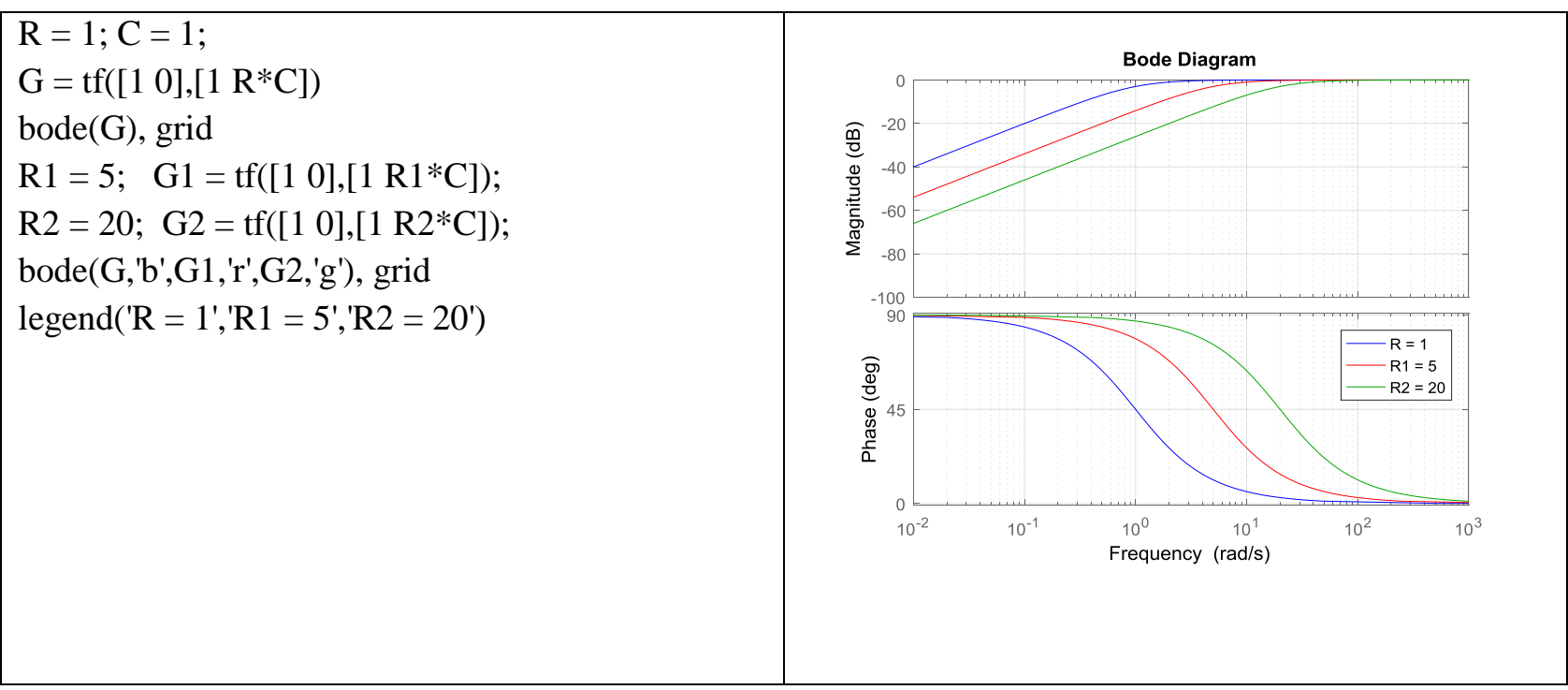

The resistor value $\mathrm{R}=1$ gives a filter narrowly tuned around the target frequency of $1 \mathrm{rad} / \mathrm{s}$. 


\section{1 analyzing the time response of the circuit}

We can confirm the attenuation properties of the circuit $G(R=1)$ by simulating how this filter transforms sine waves with frequency $0.9,1$, and $1.9 \mathrm{rad} / \mathrm{s}$ :

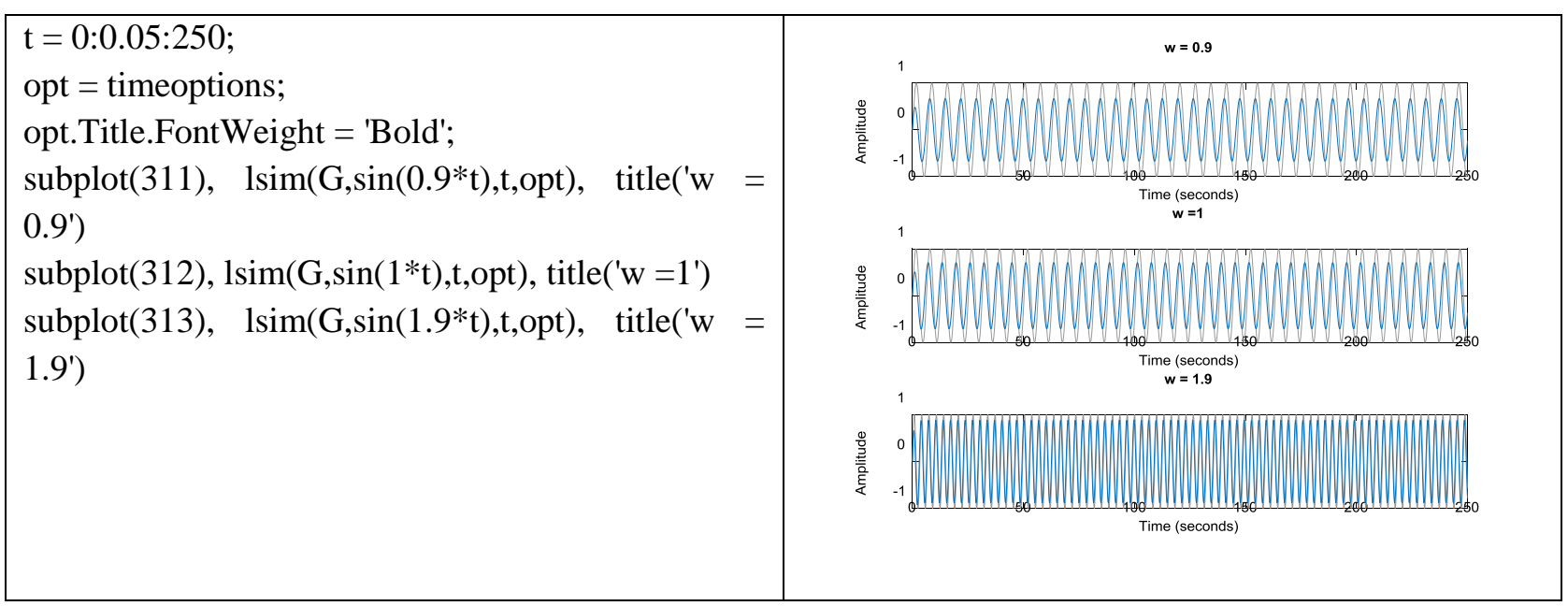

The waves at 0.9 and $1 \mathrm{rad} / \mathrm{s}$ are considerably attenuated. The wave at $1.9 \mathrm{rad} / \mathrm{s}$ comes out unchanged once the transients have died off.

\section{References}

1. http://www.mathworks.com/. Dec. 1998.

2. Matlab, Signal Processing Toolbox User's Guide. The MathWorks, Inc., 1996.

3. H.J. Orchard and G.C. Temes. "Filter Design Using Transformed Variables". IEEE Trans. Circuit Theory, Vol. 15, pp. 385-408, Dec. 1968.

4. P.L. Duren, Univalent Functions, Grundlehren der MathematischenWissenschaften Springer, New York, USA, 2591983.

5. A.W. Goodman, On uniformly starlike functions, J. Math. Anal. Appl., 155 (1991), 364-370.

6. S. Prema, B. S. Keerthi, Coefficient bounds for certain subclasses of analytic functions, J. Math.Anal., 4 (1) (2013), 22-27.

7. Robertson, M.S., On the theory of univalent functions, Itextit\{Annals. Math.\}, (1936), 374--408. 